\title{
STRESS FRACTURE OF THE FEMORAL NECK IN A MARATHON RUNNER
}

\author{
S. BAER, MB, BS and D. SHAKESPEARE, FRCS
}

Accident Service, John Radcliffe Hospital, Oxford

In the wake of recent popular interest in physical fitness (Smith, 1983), there has been an increase in exerciserelated injuries. Although the vast majority are minor musculo-skeletal problems, care should be taken not to miss the more severe injury presenting with non-specific symptoms. The following report describes a stress fracture of the femoral neck occurring in a young marathon runner.

\section{CASE REPORT}

A 36-year-old male University Lecturer presented with severe right thigh pain, present since attempting a marathon 5 days previously. The patient began training one year prior to the race and gradually increased his activities to $\mathbf{5 0}$ miles per week; mostly on hard road surfaces and wearing purpose built shoes. Two weeks before the race he developed exercise-related pain localised to the medial aspect of the right thigh. He restricted his training, in the week prior to the race, to a 60-mile cycle ride and brisk walks. During the marathon attempt the initial 5 miles were accompanied by only minimal pain; but over the next 3 miles the pain increased to such a level that he was forced to retire. Medical advice was sought but no $X$-rays were taken and the injury was not diagnosed. After a further 5 days, medical advice was again sought and at th is time examination revealed tenderness in the right groin and pain at the extremes of hip movement, passive flexion was accompanied by an audible click.

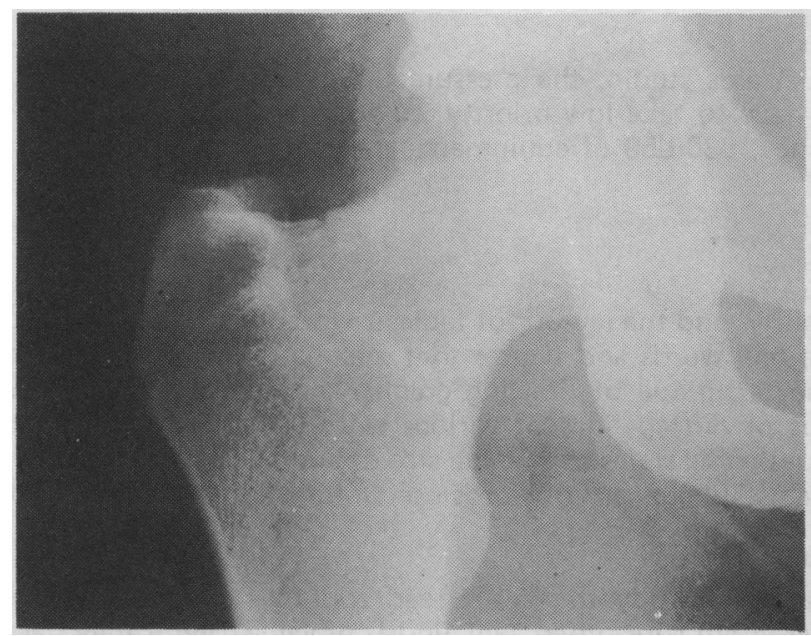

Fig. 1: Radiological appearance on presentation, showing fracture line through femoral neck.
Radiographs revealed a complete but undisplaced fracture of the femoral neck (Fig. 1). This was treated by internal fixation (a dynamic hip screw). The patient was mobilised partially weight-bearing at $\mathbf{4 8}$ hours and by 12 weeks the fracture had healed.

\section{COMMENT}

The majority of reported cases of stress fractures of the femoral neck have been in young military recruits undergoing vigorous training (Kaltas, 1981). A recent report has described the injury in young runners (Hajek and Bates Nobel, 1982).

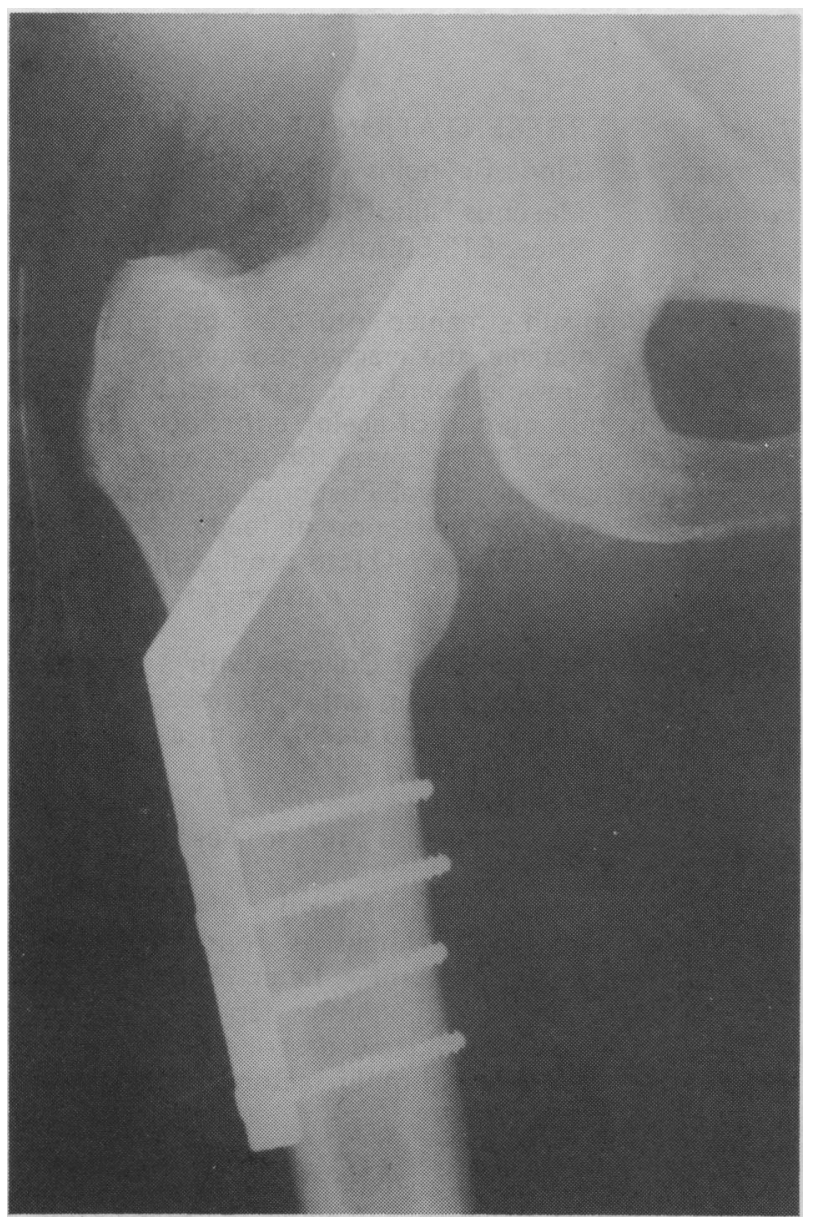

Fig. 2: Radiological appearance following internal fixation with dynamic hip screw. 
In 1965 Devas presenting the largest series of 25 patients classified the condition into 2 separate groups on radiological appearance. The "transverse" type of stress fracture begins as a crack in the superior cortex of the femoral neck. Continued loading results in a complete fracture which may subsequently become displaced. The "compression" type of stress fracture is characterised by a "haze" of internal callus or a crack at the inferior border of the femoral neck.

Devas considered the transverse fracture to be inherently unstable, requiring early internal fixation. $A$ failure to do this runs the risk of complete displacement of the fracture with the attendant technical problem of instrumentation of extremely hard bone in a young person and the risk of avascular necrosis of the femoral head. The compression fracture does not require surgery and heals with excellent results in regimes varying from no treatment at all, to prolonged bedrest (Hajek and Bates Noble).

The occurrence of increasing exercise-related pain, in the thigh or groin, in runners should raise the possibility of a stress fracture of the femoral neck. Although radiographs may be unhelpful initially, bone scintigraphy may detect an early lesion. Only a high level of clinical suspicion can lead to an early recognition of this condition and prevention of mis-diagnosis with potentially disabling sequelae.

\section{REFERENCES}

Devas, M. B., 1965 "Stress fractures of the femoral neck". J.Bone Joint Surg. 47-B: 728-737.

Hajek, M. R. and Bates Nobel, H., 1982 "Stress fractures of the femoral neck in joggers". AM J.Sports Med. 10: $112-113$.

Kaltas, D. S., 1981 "Stress fractures of the femoral neck in young adults". J.Bone Joint Surg. 63-B: 33-57.

Smith, T., 1983 "Exercise: Cult or cure all?". Br.Med.J. 286: $1637-9$.

\section{BOOK REVIEW}

Title:

\section{FOR AMATEUR BOXING - THE REPORT OF THE ONTARIO AMATEUR BOXING REVIEW COMMITTEE 1983}

Authors: $\quad$ Prof. Bruce Kidd (Chairman), Frank Corner, QC, and Dr. Bruce Stewart

Publisher: $\quad$ The Ministry of Tourism and Recreation, Government of Ontario, Canada

Price: $\$ 3$

In compiling this report, the authors have obtained information from seminars, informed sources connected with the sport, and from visits to tournaments in Canada and the German Democratic Republic.

The initial chapter outlines a historical background of boxing, including legislative discussion as applied to amateur boxing in Ontario and Canada. Ethics of boxing are discussed and contrast is exercised between the professional and amateur areas of the sport. Some neurological changes, the result of head injury in the ring are presented, although most of the evidence has been obtained from professional boxing.

In the numerical assessment of boxing injuries, comparison should be made with injuries sustained in other sporting activities.

The following fifty pages of the report deal with safety measures, registration of boxers, medical aspects, coaching and the officiating of contests as applied to Boxing Ontario.

Finally, there is a summary of the major findings of the report, several appendices of practical use to administrators of boxing, and a large bibliography. No fewer than eight references are made to the work of the late Dr. J. L. Blonstein. Dr. Blonstein was a world authority in the medical aspects of amateur boxing and in this capacity attended the Olympic Games on many occasions. He was a founder member of the British Association of Sport and Medicine.

H. Noel Bleasdale 